\title{
uma leitura de o grifo de abdera de Iourenco mutarelli como realidades múltiplas
}

\section{A reading of $O$ Grifo de Abdera by Lourenço Mutarelli as multiple realities Lielson Zeni ${ }^{1}$}

Resumo: No romance $O$ Grifo de Abdera, o autor Lourenço Mutarelli traz para o primeiro plano da narrativa um jogo de múltiplas identidades que se relacionam de modo conflituoso, mas nem por isso menos produtivo. Em uma mescla de realidade e ficção, Mutarelli propõe que ele não passa de um personagem criado por um escritor que não gosta de aparecer, interpretado por um ator. A partir disso, a carreira literária e quadrinística de Mutarelli é revisitada do ponto de vista da ilusão e da farsa, a partir de seus biografemas. Além dessa expansão da ficção para a realidade (e de volta à ficção), há também um longo trecho do romance em história em quadrinhos, além de atos performáticos, o que conduz à multiplicação das realidades a partir da ficção.

Palavras-Chave: Lourenço Mutarelli; Literatura Brasileira; História em Quadrinhos; Performance; Ficção.

Abstract: In the novel O Grifo de Abdera, the author Lourenço Mutarelli brings to the forefront of the narrative a game of multiple identities with conflituous relationships, but no less productive. In a mix of reality and fiction, Mutarelli suggests that he is but a character created by a writer who does not like being noticed, who, in turn, is played by an actor. From that, Mutarelli's literary and comic book career is revisited from the perspective of illusion and farce, taking his biographems as a starting point. In addition to this expansion from fiction to reality (and back to fiction), there is also a long excerpt of the novel as a comic book, as well as performing acts, which leads to the multiplication of realities from fiction.

Keywords: Lourenço Mutarelli; Brazilian Literature; Comics; Performance; Fiction.

1 Mestre em Letras - Estudos Literários (UFPR); Doutorando em Letras - Ciência da Literatura na Universidade Federal do Rio de Janeiro (UFRJ) - e-mail: lielson@gmail.com. 
Eu imaginava, às vezes, um Autor perverso que tivesse escrito suas obras unicamente para ter o direito de escrever, um dia, sua autobiografia.

Roland Barthes (2006, p. 169).

\section{introducão}

Lourenço Mutarelli é um autor paulistano que produz sua obra em várias frentes: ganhou notoriedade com as histórias em quadrinhos, trabalhou como ilustrador para mercado editorial e publicitário, investiu na escrita de drama, de roteiros cinematográficos e de prosa de ficção, atuou em cinema e teatro. Em O Grifo de Abdera, de 2015, ele parece revisitar boa parte dessa vida em obra, mas com as lentes da ficção. Nesse sétimo romance (além desses, ainda existe a coletânea de textos teatrais, os livros de histórias em quadrinhos e um álbum de prosa ilustrado), Mutarelli incluiu como parte estruturante de sua prosa a performance, a atuação e as histórias em quadrinhos, além, claro, do próprio texto ficcional, com muitos elementos identificáveis como autobiográficos.

O Grifo de Abdera tem uma premissa enganosa: uma moeda antiga que tem o mesmo nome do livro é entregue ao protagonista Mauro Tule Cornelli; esse gesto destrava sua escrita e o conecta sobrenaturalmente a outro homem, Oliver Mulato, e, então, essa moeda, transformada em anel, migra para outras mãos, entre personagens que se assemelham em muitos aspectos; porém, o verdadeiro embate se dá entre a multiplicidade dos personagens que se abrigam sob o avatar de Lourenço Mutarelli, uma personalidade criada por Cornelli para representar seu trabalho inicialmente com histórias em quadrinhos e posteriormente com prosa ficcional (talvez um aceno a André $\mathrm{Gide}^{2}$ ). Para isso, o processo narrativo se multiplicará por dois dispositivos publicados, nesse caso, juntos e indissociáveis, em um mesmo volume: a prosa de ficção e as histórias em quadrinhos. E também certo movimento performático que permeia a obra como um todo.

Para além do livro físico e digital da editora Companhia das Letras, a obra se desdobrou como leitura dramática musicada para promoção do

2 André Gide é autor do romance Os Moedeiros Falsos, sobre um personagem que escreve um livro em que o personagem é escritor, um mise-en-abyme - recurso metalinguístico cunhado pelo escritor francês. Outras relações de aproximação com O Grifo de Abdera seriam a ideia de falsificação, de troca de originais por cópias e do objeto moeda. 
lançamento do livro, e olhou para o passado ao incluir informações de entrevistas de Mutarelli (por exemplo, GUSMAN, 2015, p. 44) e de fatos biográficos do autor. Quero dizer, há um movimento circular: a obra de Mutarelli, que já se construía em parte de elementos biográficos, produziu o interesse dos leitores pelo autor e por sua figura, o que conduz esses leitores ao material biográfico, como prefácios, falas públicas e entrevistas; então, esse material é reaproveitado posteriormente e ficcionalizado em $O$ Grifo de Abdera, como se fosse uma performance previamente planejada. Ao incluir o que ele mesmo disse durante anos de aparições públicas e de publicações, Mutarelli ressignifica o todo ao propor que se trata de uma farsa, de um plano de criação de um personagem criador de personagens. A volta do círculo se fecha mas já não se está no mesmo ponto de origem.

Diante desse emaranhado de identidades aos fragmentos, alguns temas chamam a atenção em $O$ Grifo de Abdera, como a multiplicidade identitária, as relações de trabalho, a relação entre ficção e realidade, a construção intermidiática, a discussão sobre autoria, entre outras abordagens.

Dentre tantas leituras possíveis, a proposta deste artigo é ponderar de que forma essas opções estéticas, que são desdobramentos a partir de um centro em prosa literária, podem gerar realidades ficcionais. Para isso, se faz necessário apresentar não apenas o material de $O$ Grifo de Abdera, mas certa biografia do autor.

\section{as múltiplas atuacões}

Certa biografia do autor

O Lourenço Mutarelli que é conhecido a partir de sua vida pública de autor é um homem nascido em 1964, em São Paulo, casado com a escritora Lucimar Mutarelli, pai de Francisco Mutarelli. Antes de ser escritor, ele trabalhou na Mauricio de Sousa Produções como animador, produziu quadrinhos independentes na década de 1980, venceu o prêmio da I Bienal de Quadrinhos do Rio de Janeiro, em 1991, com seu primeiro romance gráfico Transubstanciação (Dealer, 1991; Devir, 2001; Comix Zone, 2019) e vem produzindo livros, primeiro de histórias em quadrinhos e a seguir de prosa ficcional (seu romance mais recente é O Filho Mais Velho de Deus e/ou Livro IV, de 2018). 
O próprio autor afirma em entrevistas e textos que muitos dos materiais de suas histórias são situações que ele viveu e que a produção da obra foi uma forma que encontrou para lidar com o problema: "É fruto de episódios vividos, é a certeza do incerto. Não é a luz na escuridão, mas sim o momento em que nossos olhos passam a enxergar nas trevas" (MUTARELLI, 2001, p. 12). Esses "episódios vividos" são chamados neste artigo, a partir da definição de Roland Barthes, também de biografemas. A definição do termo barthesiano seria, de acordo com Maria Clara Carneiro:

A experiência proustiana introduziria, segundo Barthes, uma "escrita de vida", que ele chama de uma "biografemática", onde o Texto fragmenta o sujeito, o divide, chegando ao ponto de uma pulverização. $O$ termo biografema, também cunhado pelo semiólogo, significaria fatos dispersos da vida de alguém. Dessa forma, cada fragmento comporia um todo homogêneo (CARNEIRO, 2007, p. 70).

Os biografemas seriam mínimos elementos biográficos que um autor dissemina ao longo de sua escrita. No caso de Mutarelli, isso pode ser percebido em estações de metrô de São Paulo que ele costuma usar, em situações que ele torna ficção e, claro, em seu próprio nome. Sabe-se que a interpretação do autor ou mesmo informações que ele dá de sua obra, até de sua vida pessoal, devem ser vistas não como verdades definitivas, mas como uma leitura da obra. Há ainda outra entrada: encarar esses textos vindos do autor como estratégia criativa, em que a própria vida é ficcionalizada para pôr luz sobre aspectos da produção literária.

No trecho de Mutarelli citado acima, que consta no prefácio à segunda edição de seu primeiro álbum, o autor carrega nas tintas românticas para dar a entender quão soturno e tenebroso foi determinado momento de sua vida; esses mesmos adjetivos podem ser usados para falar de Transubstanciação, o que gera certa assonância estilística entre paratexto e texto principal.

Há muitos biografemas bem aparentes na obra mutarelliana, não só como representação de momentos vividos e reportados em entrevistas, mas também como uso de nomes e de rostos bem reconhecíveis. Para o primeiro caso, por exemplo, o álbum Eu Te Amo Lucimar (Vortex, 1994; Comix Zone, 2019), que carrega uma declaração de amor à sua esposa no título; para o segundo, representações como do poeta Glauco Mattoso em Diomedes 
(Quadrinhos na Cia., 2012, pp.162-165) ou do próprio autor, de Lucimar, de seu filho Francisco e de seus gatos em A Caixa de Areia ou Era Dois em Meu Quintal (Devir, 2006). Ainda em Diomedes, algumas das pessoas desenhadas ali são elencadas ao final do livro, como crédito aos "atores" das encenações.

Esse Lourenço Mutarelli seguiu com a produção de histórias em quadrinhos até 2006, justamente a data de lançamento de A Caixa de Areia ou Era Dois em Meu Quintal, o que seria o ponto final de sua trajetória como quadrinista - a exceção fica por conta de pequenas participações como roteirista em coletâneas, o roteiro longo do livro O Astronauta (Zarabatana, 2010), e um livro ilustrado que foi tratado comercialmente como história em quadrinhos, tanto na ficha catalográfica quanto na divulgação, Quando Meu Pai Se Encontrou com o ET Fazia um Dia Quente (Quadrinhos na Cia., 2011).

Com a publicação de $O$ Cheiro do Ralo (Devir, 2002), o interesse criativo do autor se volta à literatura, carreira em que Mutarelli investe para deixar de lado a produção quadrinística. Com seu quarto romance, $A$ Arte de Produzir Efeito Sem Causa (Companhia das Letras, 2008), obteve o terceiro lugar no Prêmio Portugal Telecom de Literatura em Língua Portuguesa de 2009; e ainda produziu outros quatro romances, sendo o penúltimo deles $O$ Grifo de Abdera (finalista na categoria romance do $5^{\circ}$ Prêmio Jabuti, em 2016). Uma das peças de teatro que escreveu, "O Que Você Foi Quando Era Criança?" publicada em OTeatro das Sombras (Devir, 2007), foi finalista do Prêmio Shell em 2006.

O interesse pelos palcos não se circunscreve à dramaturgia, pois desde 2007 Mutarelli também vem atuando em diversos filmes e trabalhou como ator na peça escrita e dirigida por Mário Bortolotto, Música para Ninar Dinossauros, de 2010 e, assim, estabeleceu um terceiro aspecto de produção na atuação. Além do texto dramático para teatro, ele também produziu roteiro de cinema. Todos esses trabalhos, em dispositivos tão diversos, retornam ao mesmo homem, que é quadrinista, romancista, dramaturgo, roteirista e ator (deixando de lado aqui, por ora, o professor de cursos livres, ilustrador e oficineiro).

Mutarelli salta de um campo a outro de forma bastante natural. Se ele escreve e desenha os seus álbuns de quadrinhos, ele também pode ou apenas desenhar e ilustrar (como fez em a edição de A Metamorfose, de Franz Kafka) ou apenas escrever prosa de ficção sem usar imagens; se ele escreve prosa, 
então pode produzir drama também; se faz dramaturgia e convive com teatro, pode subir no palco e também atuar, e pode aprender a encenar diante das câmeras e também trabalhar na escrita das cenas de cinema baseadas nos livros que ele mesmo escreveu. É como se cada novo dispositivo acessado por Lourenço Mutarelli fosse um desdobramento simples do anterior.

E boa parte desses campos por onde o autor passeia vão ser dispostos, avaliados e colocados em perspectiva, e projetados a partir da ficção no romance $O$ Grifo de Abdera. E para um criador de personagens em prosa, drama, quadrinhos e cenas, a realidade apresenta muitas características da ficção, sobretudo, o interesse pelas histórias; venham essas histórias de onde vierem; sejam essas histórias fabuladas ou catalogadas.

\section{Certa biografia ficcional do autor}

Em O Grifo de Abdera, o narrador em primeira pessoa usado na maior parte do romance, em tom confessional, diz ser Mauro Tule Cornelli, que tem um pseudônimo para publicar seus romances e que pela primeira vez lançou um livro com seu próprio nome, o romance de ficção científica "Uma Ocasião Exterior". Mas o estratagema, já bastante utilizado por todo o meio literário ao longo da história, com as mais diversas motivações, ganha outros pontos de ancoragem na realidade interna do romance. Cornelli, antes de ser romancista, foi roteirista de quadrinhos e fazia dupla com o desenhista Paulo Schiavino.

Quando comecei a escrever, fazia roteiros para histórias em quadrinhos e, no dia em que a editora pediu uma foto para divulgação, eu tremi na base. Sou um cara tímido. Não achava relevante ter minha cara com a mão no queixo estampada em meus livros. Então, nesse dia em que J. Carlos, meu primeiro editor, pediu a tal foto, me ocorreu uma ideia (MUTARELLI, 2015, p. 17).

A tal ideia de Cornelli é usar a foto de outra pessoa em vez da sua. Ao perguntar ao desenhista Schiavino se ele aprovaria a troca, surge uma nova ideia: "Por sorte o Paulo, que era ainda mais tímido que eu, concordou. Mais que isso, sugeriu: Por que não criamos um personagem?" (MUTARELLI, 2015, p. 20). E então, a "partir de um anagrama de meu nome [Mauro Tule Cornelli], 
eu e o Paulo criamos um autor. Lourenço Mutarelli. Assim assinamos nossa primeira parceria" (MUTARELLI, 2015, p. 22).

Portanto, na realidade dentro do livro, Lourenço Mutarelli não é apenas um personagem de autoficção de outro Lourenço Mutarelli, situado em uma realidade externa a $O$ Grifo de Abdera. Ele é um personagem criado por outros personagens como pseudônimo de seus trabalhos criativos, e seus biografemas apresentados na obra são ações de um personagem não autoficcional, mas de um engodo criado por outros dois personagens. Schiavino e Cornelli ainda vão adiante com a ficcionalização de sua carreira literária na realidade interna do livro, pois já que ambos se dizem tímidos e não gostam de aparecer em público, alguém precisa fazer isso por eles.

O terceiro membro do grupo, que seria o responsável por dar a carne ao corpo de Lourenço Mutarelli, é Raimundo Maria Silva, o Mundinho, um apontador de jogo do bicho e pequeno traficante que pode sempre ser encontrado no Bar do Marujo. A descrição física do personagem em sua apresentação ao leitor diz apenas "Mundinho é um cara descolado, ginga de malandro e uma cara feia mas muito mais expressiva do que a minha. Achei que podia ser bacana ter a sua cara no lugar da minha. [...] Depois de relutar um pouco, Mundinho acabou topando em troca de uma dose de pinga" (MUTARELLI, 2015, p. 20).

Enquanto Mauro e Paulo fariam as histórias em quadrinhos, Mundinho seria seu avatar para entrevistas e eventos, e toda a farsa estaria encarnada sob o nome de Lourenço Mutarelli. "Assim, a solução provisória para o problema do indivíduo em $O$ Grifo de Abdera, que dá a possibilidade da escrita de um romance, é a unificação de toda a fragmentariedade da existência de Mauro através da criação de um pseudônimo" (CASTANHO, 2018, p. 30). Parece interessante confrontar a permanência do nome do autor, ainda que como farsa, com as palavras de Philippe Lejeune: "As formas do pacto autobiográfico são muito diversas, mas todas elas manifestam a intenção de honrar sua assinatura. [...] Sabe-se muito bem o quanto cada um de nós preza seu próprio nome" (LEJEUNE, 2008, p. 26).

Lourenço Mutarelli brinca com esse apreço ao próprio nome ou realmente trata de uma ação de valorização de si? Provavelmente, ambos. Ao colocar a si mesmo como uma farsa, a encarnação do pseudônimo, Mutarelli traz para perto de sua figura a discussão sobre a valorização do nome autor; nesse 
caso específico, de seu nome. O processo todo revisita a carreira dele, dá a ver quantas obras ele produziu, a longevidade de seu trabalho criativo e a diversidade desse trabalho.

As obras citadas por Mauro, produzidas por Paulo e ele sob disfarce do pseudônimo, têm o mesmo nome das obras publicadas pelo autor Lourenço Mutarelli no universo fora da ficção do romance, até mesmo com coincidência de datas. E nesse encontro forjado ficcionalmente entre as realidades internas e externas ao romance, o leitor repassa pela produção do autor. Porém, se esse hipotético leitor resolver ler (ou mesmo se já leu) Transubstanciação, por exemplo, é como se acessasse duas obras simultaneamente, uma oriunda da realidade externa ao livro, mas ao mesmo tempo, uma que vem da realidade interna de O Grifo de Abdera. Uma escrita por Mauro Tule Cornelli e lançada sob o pseudônimo de Lourenço Mutarelli e a outra lançada por Lourenço Mutarelli; ambas com o mesmo texto, palavra por palavra, mas diferentes, pois seu contexto de entendimento a partir do autor muda. É como se os biografemas de Mutarelli fossem hackeados por seu personagem-narrador. Lourenço Mutarelli atua como um Pierre Menard de sua própria obra, e usa o leitor para dar cabo dessa manobra borgeana.

Um evento trágico explica a mudança dos quadrinhos para a literatura na realidade de $O$ Grifo de Abdera: a morte de Paulo Schiavino por atropelamento em 30 de outubro de 2005, um dia depois de concluir o livro de história em quadrinhos A Caixa de Areia Ou Era Dois em meu Quintal, publicado no ano seguinte. "Com a morte de Paulo, tive de me virar sozinho, por isso abandonei os quadrinhos e passei a escrever livros" (MUTARELLI, 2015, p. 22). E haveria uma coincidência entre a realidade dentro do romance e a ficção dentro do romance quanto à primeira foto de Mundinho no papel de Lourenço Mutarelli:

Quanto a Mundinho, nem precisamos tirar a foto. Quando explicamos o plano, ele disse que tinha uma "da hora" que um colega seu tinha feito.

A foto era emblemática o bastante e a usamos em nosso álbum de estreia, Transubstanciação. A foto mostra Mundinho caído de bruços num trilho de trem. Mundinho disse que foi tirada em Peruíbe. [...]

Na foto da perícia a pose de Paulo morto era idêntica à de Mundinho no trilho do trem (MUTARELLI, 2015, p. 22). 
A foto citada no livro foi usada na quarta capa da primeira edição de Transubstanciação no lugar da foto do autor e mostra Lourenço Mutarelli caído em meio aos trilhos de trem (ver Figura 1). A imagem não é apresentada em O Grifo de Abdera, mas descrita. Essa foto traz um bom exemplo da multiplicação das realidades internas e externas ao romance a partir de um jogo de criação de duplos de Mutarelli, mesmo que esse duplo seja esvaziado de vida como um pseudônimo.

FIGURA 1

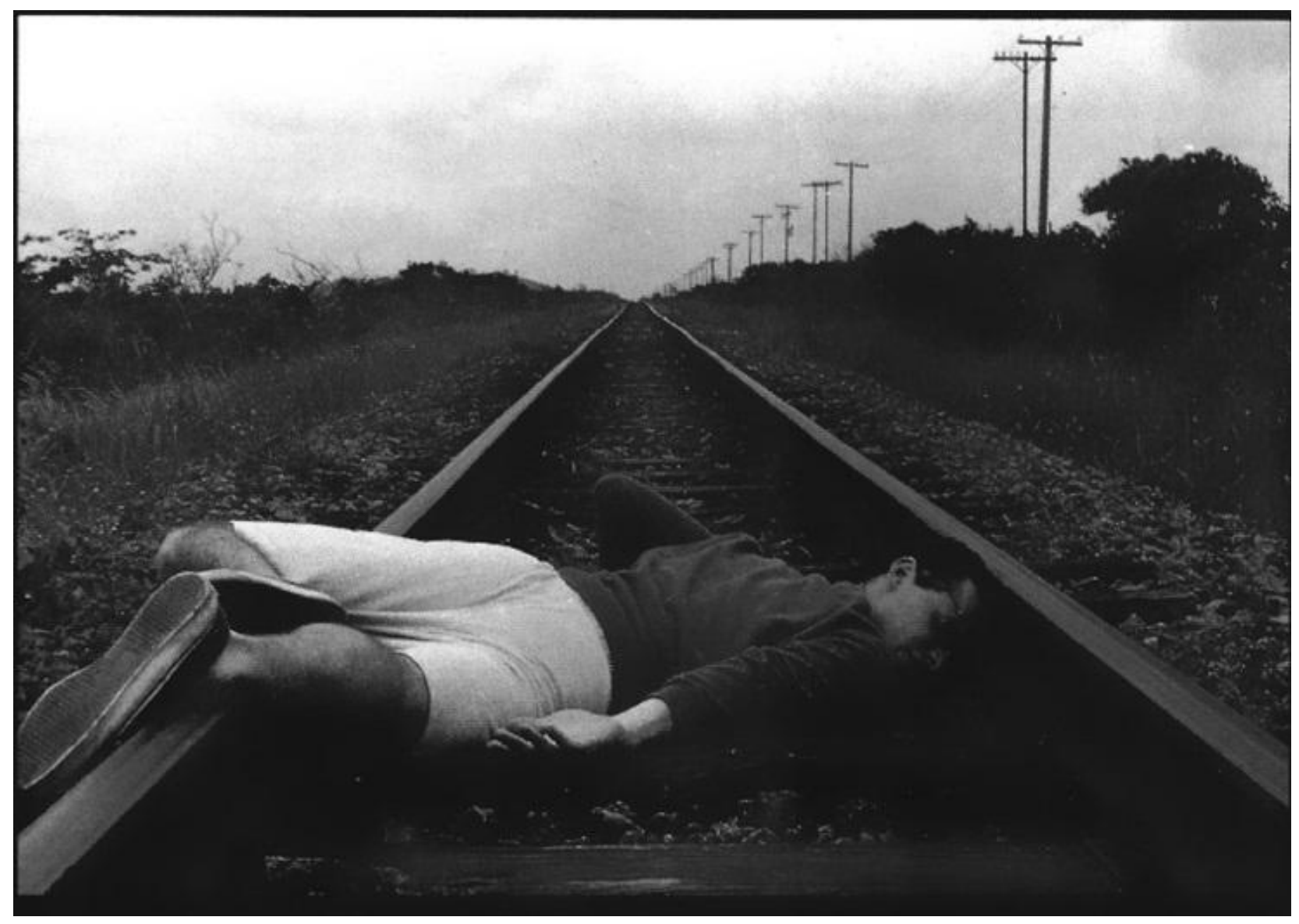

Foto de Lourenço Mutarelli na quarta capa de Transubstanciação (MUTARELLI, 1991); ou foto de Mundinho em Transubstanciação, primeiro trabalho da dupla Paulo Schiavone e Mauro Tule Cornelli sob o pseudônimo Lourenço Mutarelli.

Na realidade externa ao livro, Lourenço Mutarelli posou para a foto que consta na quarta capa de Transubstanciação; na realidade interna do livro quem posou foi Mundinho, mas a imagem foi divulgada como se fosse de Lourenço Mutarelli. Ao colocar o corpo morto de Paulo Schiavino em uma posição que lembra os dois Mutarellis ao mesmo tempo, um via ficção, outro via biografema, sem ser nenhum deles, mas ao mesmo tempo ambos, o autor reforça essa divisão de realidades pela aproximação de realidade e ficção. 
A tentativa de independência de Mauro de seu autor passa, no caso do romance, por inverter a relação entre autor-personagem e tornar-se ele personagem, o criador de Mutarelli. Esse procedimento de Mauro é uma espécie de autoconsciência de ele ser um personagem, uma compreensão de que ele existe em uma realidade ficcional e da qual ele não tem controle. A narrativa em primeira pessoa de Mauro segue e tem ainda outro elemento de união e, ao mesmo tempo, fragmentação das personalidades ao redor do nome Lourenço Mutarelli: o personagem Oliver Mulato, outro nome que parece derivar da variação das letras do nome de Lourenço Mutarelli ou de Mauro Tule Cornelli (depende de qual realidade é levada em conta), ainda que sem usar todos os caracteres. Entretanto, se trata de uma ponte diferente entre realidade exterior e interior ao livro, outro biografema.

Surgido como uma encomenda, $O$ Grifo de Abdera deveria servir de base para uma adaptação cinematográfica, e havia um pedido de produção para que um personagem fosse designado ao ator Otávio Müller. O Lourenço Mutarelli da realidade fora do livro brinca com isso e cria um anagrama do nome do ator e assim surge Oliver Mulato, o duplo de Mauro. O Mutarelli da realidade externa segue usando os biografemas, sejam eles do acaso ou não, como matéria da composição da ficção.

Mulato é um personagem de Mauro que existe também na realidade dentro do livro e não apenas na ficção dentro da realidade ficcional, a ponto de haver cenas de encontros entre eles e Mundinho no romance. Oliver Mulato é um personagem semelhante fisicamente a Cornelli "Embora as pessoas não percebam, nós somos idênticos. Isso me espanta. Somos fisicamente idênticos e ninguém se dá conta disso." (MUTARELLI, 2015, p. 19). E mais do que isso, Mauro diz ser Oliver: "Se alguém me desse ouvidos, saberia que, embora eu seja eu, também sou, ao mesmo tempo, Oliver Mulato." (MUTARELLI, 2015, p. 16).

Mauro exerce certo poder sobre seu personagem Oliver, em mais uma evidência de que nessa obra a ficção guia a realidade e não o contrário. Oliver não é apenas alguém que é observado por Mauro e então transposto para uma existência ficcional, mas é também acessado por ele, que passa a ver e vivenciar, ainda que por instantes, o mundo a partir da vida de Oliver, mesmo que sem a intenção inicial do autor. 
No início, viver esse fenômeno, ter a consciência de Oliver, me virava o estômago. Como numa linha cruzada, meu raciocínio era confundido, no caso pelas visões, e eu sentia vertigem. [...] Imagino que seja difícil compreender o que é ter duas consciências. Mais difícil ainda é explicar. Porque não sou, não somos, dois integralmente. Nem um. [...] E, se não me cuidasse, era como se eu fosse completamente absorvido pela consciência dele. Porque, de qualquer forma, minha consciência era sempre mais presente. Dominante. [...]

Escrever sobre essa estranha experiência me aproxima de mim. Acalma as visões e silencia as vozes. Não tenho, e acredito que nunca terei, controle sobre o fenômeno (MUTARELLI, 2015, pp. 56-57).

Mais que isso, Cornelli interfere diretamente na vida de seu personagem, que sofre de síncopes, em que desanda a falar impropérios em espanhol sem ter controle do que diz e de como parar. O diagnóstico de Oliver no livro é de que sofre da síndrome de Tourrete. Porém, a causa desses rompantes não é um distúrbio psiquiátrico, e sim, o autor Mauro.

E tudo isso por culpa minha. Se eu pudesse imaginar que um pequeno hobby iria um dia chegar a se manifestar através de um, até então, estranho [Oliver Mulato], nunca teria brincado com o Google Tradutor.

Porque era isso. Ora digitava frases quando estava irritado, ora me excitava ao ouvir aquela voz dizendo coisas obscenas. As frases mais engraçadas eu copiava e colava no Word (MUTARELLI, 2015, p. 21).

Oliver gritava exatamente as frases colecionadas por Mauro; ele melhora não com a eficácia do tratamento proposto pelos médicos, mas quando o estoque de frases no documento de Word termina. O fim dos impropérios leva também ao fim da relação de duplo entre Mauro e Oliver, e segue para a morte deste e o encerramento do livro por aquele. O fim, entretanto, é algo para o que Mauro não está preparado: "Terminar um livro é uma mistura de alegria e tristeza. Uma realização acompanhada de vazio. É um mundo que não voltamos a visitar. É uma despedida." (MUTARELLI, 2015, p. 253).

Diversos fins são colocados nas páginas finais do romance, uma insistência em dizer que se acabou, mas o texto prossegue em seguida, como se resistisse a se concluir, como se não aceitasse seu fim. 
É este fim, que insiste em retomar a página, sempre como novo subterfúgio, a realização performática que encerra o livro, cuja importância da ação não está, propriamente, no desenlace, mas no processo. A performance nãobusca conclusão. Intencional ou não, é interessante notar que Lourenço Mutarelli, quando realmente termina o livro, não usa a palavra FIM. Mauro Tuli Cornelli conta que está com o anel em seu dedo e a frase se repete: "Todo livro é uma despedida" (Mutarelli: 2015, 255). (MOTA, 2016, p. 145).

Mota aponta para o grau performático dessa atitude de Lourenço Mutarelli da realidade exterior ao livro. Eu acrescentaria ainda o ato na realidade interna do livro, ato de tamanha lucidez de Mauro, que começa a entender que ele não é autor, mas personagem, e que o fim do romance é seu fim, que sua existência na realidade ficcional dentro do livro só é possível se ativado por um leitor, por alguém que leia as palavras e que por meio desse processo dê vida a todos aqueles seres imaginados pelo Lourenço Mutarelli exterior ao romance. "Descobri [...] que há em minha obra vozes que, embora me pertençam, não são a minha. Foi nesse ponto que descobri que sou, quando e enquanto escrevo, mais Lourenço do que Mauro." (MUTARELLI, 2015, p. 41).

Essa percepção está em $X X X$, obra de Oliver Mulato em quadrinhos. Ali, ele percebe a posição de duplo, que há um personagem na história que usa suas falas. Embora a história em quadrinhos exponha esses conceitos, Oliver não parece ter consciência deles, como se essa percepção estivesse reservada ao inconsciente do quadrinista e vazasse pelos desenhos. Há uma divisão entre o que é mostrado e o que o personagem sabe.

Renata Manoni de Mello Castanho, na dissertação sobre O Grifo de Abdera, pondera sobre outra cisão importante: a de Mauro como narrador e a de Mauro como personagem

Seja qual for a postura que se queira ter em relação ao Mauro-narrador, é evidente a disparidade entre ele e o Mauro-personagem. O controle que ele mostra ter sobre a sua escrita não corresponde ao controle que tem sobre a sua própria vida - e isso é fundamental para entendermos Mauro e Lourenço como nomes que aglutinam mais personagens sob uma mesma máscara, de maneiras diferentes. Se, quando vive a sua narrativa, Mauro é ao mesmo tempo ele mesmo e Oliver, dois personagens enfraquecidos e sem controle sobre as próprias vidas, ao escrever 
muda de nome e passa a ser o "bem-sucedido" escritor Lourenço Mutarelli [...]. Além disso, este recurso contribui para a noção de que a escrita constrói a vida, e que por isso a precede, o que ajuda a entender a relativização ou mesmo a inversão entre real e ficção que tantas vezes é trabalhada no livro... (CASTANHO, 2018, p. 27).

No caso desse romance, a escrita de Mutarelli não apenas precede a vida, mas cinde a realidade e a multiplica. E, apesar de a moeda grifo de Abdera ser um mote falso para a história, é justamente ela que fará o encerramento doromanceapós darinício aolivro, pois somente quando Mauro recebe a moeda de um estranho é que quebra seu bloqueio e volta a escrever, justamente, O Grifo de Abdera (vale observar que Mundinho manda um amigo entregar a moeda para Mauro, como uma brincadeira, da mesma forma que Mutarelli entrega ao leitor um livro que falseia e diz não ser seu). No momento em que Mauro retoma a moeda fundida no anel que estava com Mundinho, o livro acaba, mas não a realidade expandida surgida ali. Circular como uma moeda.

O fim do livro não é o fim dos desdobramentos de O Grifo de Abdera.

\section{um romance não apenas literário}

O Grifo de Abdera faz diversas insinuações entre as realidades internas e externas ao livro, como o uso dos mesmos nomes entre personagens e obras de uma e outra, de biografemas de Lourenço Mutarelli, o que gera um embaralhamento entre ficção e não ficção. Ao criar um duplo, Mauro Tule Cornelli que atua como se fosse Mutarelli, o autor duplica sua obra. Todo leitor que tenha lido um livro de Mutarelli também leu um livro de Cornelli, todas as entrevistas do autor foram também dadas por Mundinho em outra realidade. Portanto, a multiplicação de personagens no romance leva à multiplicação das realidades e das obras.

Os biografemas de Mutarelli passam a ser ficção dentro da realidade interna do livro por conta do artifício da transformação da biografia do autor, não somente em material ficcional para ser usado de forma prática, mas em um embuste. 
A própria inclusão da história em quadrinhos em meio ao livro escrito por Mauro, que diz não saber desenhar, leva a uma justificativa: seria o zine que Oliver desenhou sendo lido pela personagem Marina.

Aqui, deveria entrar o Livro II. O encarte fac-similado de XXX. Seria o momento oportuno, porque vocês teriam a sensação de Marina ao descobrir esse trabalho emblemático. Mas antes, eu gostaria de chamar a atenção para alguns detalhes. A primeira coisa é o fato, já mencionado, de que, mesmo Oliver não tendo a consciência de minha existência, ou melhor, de minha coexistência, sua HO trata sobre o duplo (MUTARELLI, 2015, p. 74).

Além de todo o ferramental da construção ficcional, o autor do livro usa os paratextos e a divulgação, o que normalmente cabe à editora. Há até mesmo um perfil de Facebook para Mauro Tule Cornelli, cuja foto do perfil é Lourenço Mutarelli maldisfarçado.

\section{A expansão pelo paratexto e pela divulgação}

Logo nas primeiras páginas do livro, o leitor encontra quatro nomes como se fossem os autores do romance, nesta ordem: "Lourenço Mutarelli, Mauro Tule Cornelli, Oliver Mulato \& Raimundo Maria Silva" (MUTARELLI, 2015, p. 3). O jogo segue para o outro lado do livro e, na última página do volume, na ficha técnica e ficha catalográfica, há a inserção dos outros nomes como autores, a ponto de o ISBN não ser apenas em nome de Lourenço Mutarelli, mas de "Lourenço Mutarelli... [et al.]" (MUTARELLI, 2015, p. 272). A brincadeira segue para o site da editora. Ao visitar a página destinada ao romance, os quatro são citados como autores. Renata Manoni de Mello Castanho (2018) chama a atenção, porém, para o fato de que na capa o nome é único: Lourenço Mutarelli (bem como na lombada).

Na biografia do autor, o texto segue o padrão da editora, porém a foto da sessão traz Lourenço Mutarelli acompanhado do ator Nilton Bicudo (ver Figura 2), que atuou em 2008 na adaptação teatral de Mário Bortolotto para o romance de Mutarelli, O Natimorto: Um Musical Silencioso (DBA, 2004i Companhia das Letras, 2009). Esse trabalho rendeu-lhe uma indicação ao Prêmio Shell de Melhor Ator. Na realidade interna do livro, trata-se de Mundinho e Mauro Tule Cornelli. 


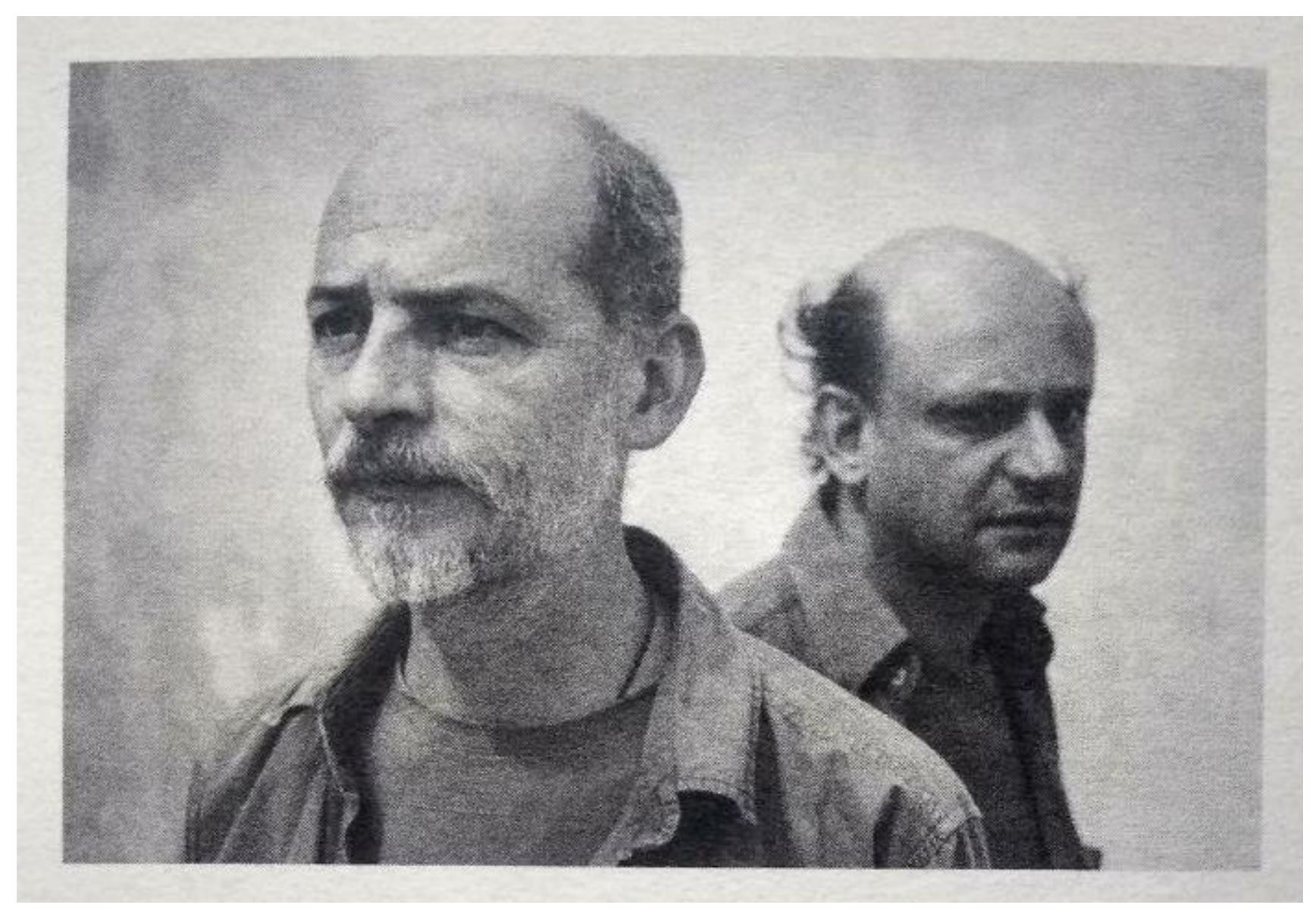

Lourenço Mutarelli (frente) e Nilton Bicudo (fundo) junto da biografia do autor em $O$ Grifo de Abdera (MUTARELLI, 2015, p. 270); ou Mundinho e Mauro Tule Cornelli.

O mesmo ator dividiu palco com Mutarelli no espetáculo de lançamento do livro realizado no Sesc Pompeia, em São Paulo no dia 11 de novembro, chamado Spoiler. Na ocasião, houve leitura do capítulo final acompanhada de um músico e gravação em vídeo.

O jogo dos duplos aqui é expandido pela presença do autor e do ator. Além de estar na foto da biografia, Bicudo está escalado para interpretar a versão cinematográfica de O Grifo de Abdera, dirigida por Fernando Sanches, a quem o livro é dedicado (MUTARELLI, 2015, p. 5). Vale notar também a data escolhida, 11/11, com dois pares de 1, quatro algarismos, a mesma quantidade de autores do livro conforme a página 3.

Ao criar acontecimentos no mundo externo ao livro, mas que remetem a O Grifo de Abdera, desenvolve-se, de certa forma, uma performance que solidifica a realidade interna ao livro. "Porque a literatura é performance, se faz agir, se reverbera. Porque a experiência da literatura pede um leitor participante." (MOTA, 2016, p. 143). As reverberações são tantas que chegam a constituir outra realidade. 
Quando Mutarelli traz para a realidade exterior do livro elementos como sósias (Nilton Bicudo) ou o anel com a moeda do grifo de Abdera, ele corporifica a realidade interior do romance. Para Lia Duarte Mota, a performance não se localiza somente nos corpos presentificados, mas também na diversidade de mídias e suportes

\begin{abstract}
Assim, para eles [os personagens] a experiência da escrita literária está relacionada a sensações físicas que produzem movimentos do corpo, das palavras, da estrutura textual. Logo, que rompem com a estrutura clássica, que escavam a linguagem em busca de uma literatura menor, que se apropriam de diferentes fontes, mídias e suportes. Uma escrita performática, inseparável da presença do corpo. Corpos que se desafiam, que buscam ultrapassar limites internos e externos - fisiológicos, psicológicos, sociais -, que se apresentam e se presentificam na escrita (MOTA, 2016, p. 152).
\end{abstract}

E XXX é relevante na ação performática que causa a multiplicação de realidades.

\title{
O quadrinho no livro
}

É Oliver quem vai produzir a história em quadrinhos $X X X$ na realidade ficcional do livro, que corresponde ao segundo capítulo de $O$ Grifo de Abdera, chamado de "Il. O Livro do Duplo". Na realidade externa ao romance, é reconhecível o traço e o estilo de Lourenço Mutarelli na história em quadrinhos. Já foi dito anteriormente que a história em quadrinhos é apresentada por Mauro como foi feita por Oliver, em uma espécie de tributo ao personagem. Mas Castanho vê um propósito narrativo como motivação do autor ao incluir o quadrinho:

A incorporação de XXX ao romance mostra que a vida mental de Oliver é mais complexa e conturbada do que as palavras de Mauro conseguem demonstrar. As frases enunciadas pelos personagens da $\mathrm{HO}$, que parecem sem sentido quando inseridas ali, se assemelham muito e por vezes são idênticas àquelas ditas por Mauro quando ele transmite sua sensação de ser ao mesmo tempo duas pessoas, e por isso ganham outro sentido ao serem associados ao romance (CASTANHO, 2018, p. 53). 
Ao colocar em outro dispositivo o que seria uma espécie de monólogo ou fluxo de consciência do personagem, Mutarelli diferencia esse personagem dos demais, pois ele é o único que se dá a conhecer pelos processos mentais. Mauro, que escreve o livro, merece todo o peso de ser um narrador não confiável; de Mundinho e Paulo sabemos por Mauro; e Lourenço Mutarelli não existe, pois é todos eles.

Mas, mesmo ao expor sua consciência via história em quadrinhos, não é possível apreender de forma fácil o que acontece com Oliver Mulato, pois

Em Mutarelli, uma vez que a experiência do real é necessariamente mediada pela literatura e pela convenção, a opacidade do real se reflete na opacidade da linguagem, levada ao extremo pelas noções da incomunicabilidade e insuficiência da escrita, colocadas como construções propositais, uma vez que são permeadas de um tom de deboche autoirônico (CASTANHO, 2018, p. 99).

Oliver tem diversos problemas de enunciação durante o livro e a opacidade de sentido de $X X X$ é apenas outro episódio. Mauro diz entender o que acontece na história, mas que muito da compreensão se perde pela falta de cores, pois luvas amarelas marcariam os duplos na história em quadrinhos.

Além de parte importante no jogo de multiplicação de realidades e autores, a história em quadrinhos faz diversas alusões biografêmicas a Lourenço Mutarelli. No romance há uma explicação do método empregado por Oliver Mulato para fazer o fanzine, bem como os créditos de onde as imagens teriam sido copiadas: o desenhista senta diante de filmes pornográficos antigos e quando algum fotograma do filme chama sua atenção o filme é paralisado e a cena é desenhada e tirada do contexto pornográfico; esse processo vai se repetir por um longo período de tempo, calhando em diversas sessões e filmes diferentes, e a relação entre todas as imagens vai se dar pela sequência e por truques visuais como as já citadas luvas amarelas. Essa explicação coincide com as explicações de Mutarelli para os desenhos em seus cursos no Sesc Pompeia e em entrevistas (como em MUTARELLI, 2015b).

$X X X$ trabalha a questão do duplo e de uma realidade em constante mutação, em que a história dá a ver parte do processo de produção. O protagonista é um homem de bigode, o Professor, porém, como os quadros não provêm 
do mesmo modelo, mas de diversos, algumas poucas características como essa são estáveis. O desenrolar narrativo tem forte ambientação onírica, em que a variação ambiental e de personagens não precisa seguir as regras do tempo e espaço da física, o que explica em parte a obscuridade de enredo.

\section{FIGURA 3}

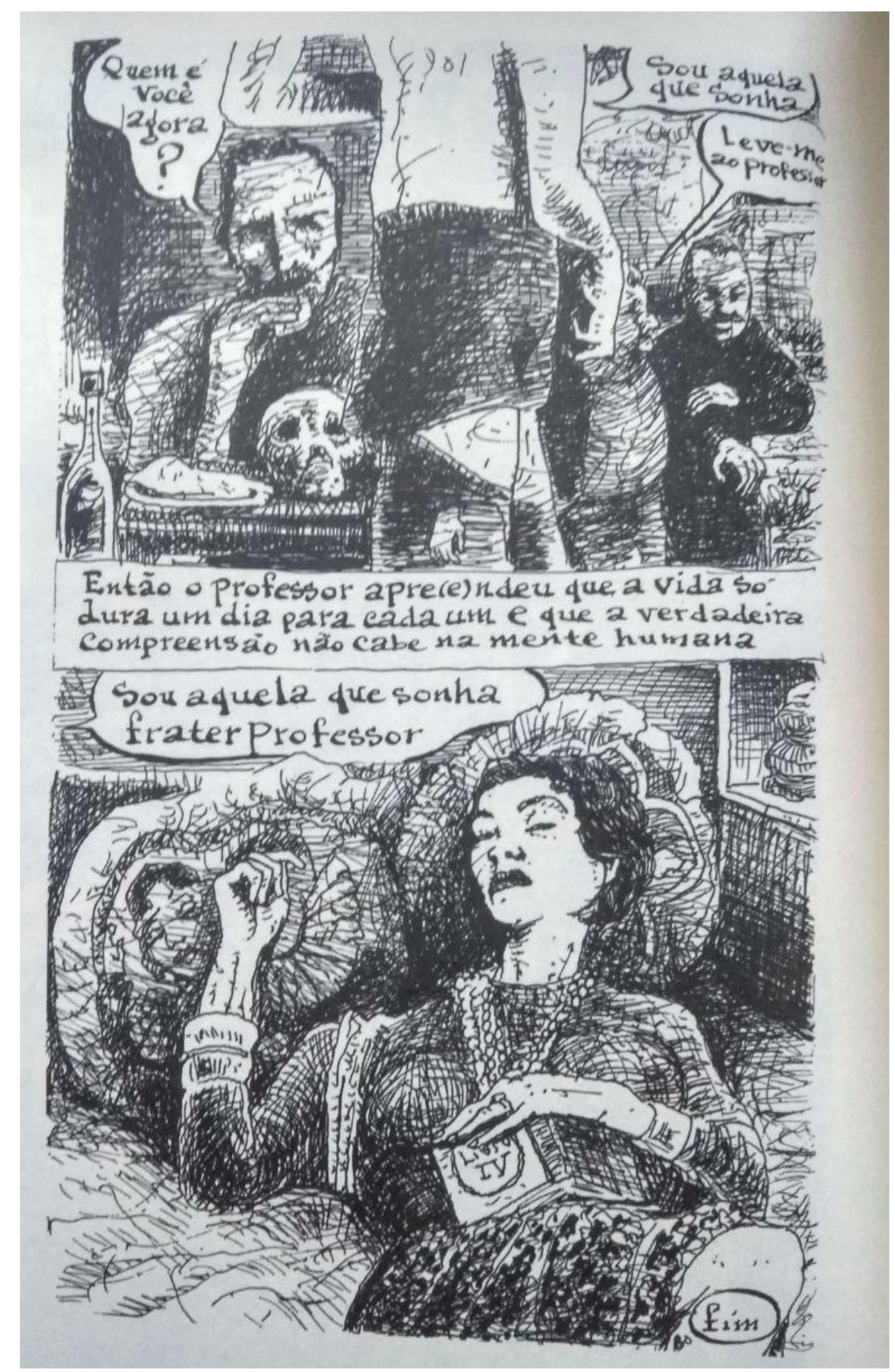

A página final de $X X X$ (MUTARELLI, 2015, p. 190)

As histórias em quadrinhos podem ser entendidas como um dispositivo em que as imagens estão em relação de colaboração entre si. "Se quisermos propor a base para uma definição razoável para a totalidade das manifestações históricas do meio [...] faz-se necessário reconhecer como único fundamento ontológico dos quadrinhos a conexão de uma pluralidade de imagens solidárias." (GROENSTEEN, 2015, p. 27). Portanto, mesmo 
com a opacidade de sentido, entende-se uma solidariedade, uma relação entre as imagens de uma história em quadrinhos. Quanto aos enunciados de textos verbais, eles podem ser encarados também como imagens, dada a importância do desenho da letra e da posição espacial que ocupam no desenho (ver Figura 3). O seu sentido lexical vai ser depreendido e influenciado, inclusive, por essa apresentação gráfica.

As imagens solidárias, porém, têm relações tênues entre si em $X X X$, o que não impede que elas tragam algum tipo de informação ao leitor. Elas mantêm uma relação dialética, o que Sergei Eisenstein chamou de justaposição

...dois pedaços de filme de qualquer tipo, colocados juntos, inevitavelmente criam um novo conceito, uma nova qualidade, que surge da justaposição. Esta não é, de modo algum, uma característica peculiar do cinema, mas um fenômeno encontrado sempre que lidamos com a justaposição de dois fatos, dois fenômenos, dois objetos (EISENSTEIN, 2002, p. 14).

A dificuldade da compreensão de $X X X$ advém em parte do próprio funcionamento da linguagem das histórias em quadrinhos: as imagens estão em relação solidária, mas essa relação não é óbvia; e pelo processo de justaposição a leitura nos leva a inferir sentido das imagens juntas, entender ali uma continuidade. Quando essa continuidade não se mostra tão aparente, há certo desencadeamento dos acontecimentos na leitura, a obstrução da narrativa.

Essa narrativa aos soluços combina com o sonho citado na Figura 3, bem como a noção de que é na história em quadrinhos que acessamos o inconsciente de Oliver. Mas ao se considerar que no mundo externo ao livro quem produziu as artes foi Lourenço Mutarelli, pode-se especular que $X X X$ na verdade entrega parte do processo de $O$ Grifo de Abdera. Não se trata de uma parte anexa, mas do próprio ponto de surgimento da história. As falas de Mauro que reaparecem no quadrinho, na verdade, surgiram no quadrinho e são depois reaproveitadas no romance; não à toa está na parte central do volume, $X X X$ é o núcleo do livro e, possivelmente, seu conteúdo mais autobiográfico (e por isso, para proteção de sua intimidade, tão cifrado por Mutarelli). De volta às entrevistas de Lourenço Mutarelli na realidade exterior ao livro e a encontros como seus cursos no Sesc Pompeia, em São 
Paulo, sabe-se que esse processo todo de desenho que se tornou a história em quadrinhos $X X X$ foi o disparador do processo criativo da escrita do livro.

\section{consideracões finais}

Poderíamos pensar em $O$ Grifo de Abdera como uma obra que se insere no campo estendido da literatura, pois ao se considerar os processos formativos do romance que passam pela história em quadrinhos e por ações performáticas são elementos que não parecem configurar uma obra literária.

Sobre a escultura, Rosalind Krauss disse: "Parece que nenhuma dessas tentativas, bastante heterogêneas, poderia reivindicar o direito de explicar a categoria escultura. Isto é, a não ser que o conceito dessa categoria possa se tornar infinitamente maleável." (KRAUSS, 2008, p. 128). Quando a autora pensa em como a escultura varia seus modelos de construção e apresentação e, a partir desse fato do mundo, em vez de negar tais obras como esculturas ela propõe que houve uma expansão do campo de ação desse dispositivo, e, dessa forma, ela também dá um passo para a expansão crítica. Ou seja, em vez de entrincheirar-se em conceitos já estáveis e negar a chancela de "escultura" às obras que não apresentassem esses conceitos, Krauss pensa em que situação elas seriam "esculturas".

Propondo uma atitude crítica semelhante, é preciso ponderar que os atos estéticos de construção ligados ao romance, embora pouco usuais, de modo algum são completamente estranhos ao campo literário - elementos como a mescla com histórias em quadrinhos, uso estético e ficcional dos paratextos, expansão ficcional pela divulgação, são ações já vistas em outras obras de outros autores. A menos, claro, que se pense em investir em uma atitude crítica mais conservadora quanto a formatos. Aliás, por mais que o uso de quadrinhos em meio ao romance possa ser percebido como um campo literário estendido, não defendo que um álbum de quadrinhos se configure como expressão literária, mesmo em condições de expansão de campo. As histórias em quadrinhos são um dispositivo diferente, cuja extensão de campo aponta a outros lugares 3 .

3 Para mais informações sobre a questão, sugiro a leitura da dissertação de Mestrado de Pedro Franz Broering, Incidente em Tunguska, e o artigo de Domingos Isabelinho "Comics' Expanded Fields and Other Pet Peeves". 
Já a confusão entre realidades, a biográfica e a ficcional, embora também já vista antes em algumas obras literárias, parece, em um primeiro momento, ter um grau de distância maior do que se espera do campo literário de modo geral, a saber: um livro de texto composto por um autor, impresso e vendido por uma editora

[...] uma indistinção ou indiferenciação entre o ficcional e o real, como se nesse texto - como em muitas outras dessas práticas do não pertencimento - a negativa a se articular de modo fechado e a colocar limites entre a realidade e a ficção fosse um modo de apagar as fronteiras entre esse mundo autônomo que seria a obra e o mundo exterior em que essa obra é lida ou percebida (GARRAMUÑO, 2014, p. 21).

Mas ao se encarar cada um desses elementos como fragmentos de um ato performático em cujo centro está o romance, há um projeto literário que foge dos limites esperados do campo literário e, para ainda ser tratado por literatura, é preciso expandi-lo. E não há dúvidas de que o livro foi tratado como literatura: as resenhas de jornal e a editora o tratam por romance, foi finalista do prêmio Jabuti na categoria romance, os trabalhos acadêmicos tratam O Grifo de Abdera como romance.

Poderia se argumentar que todas essas evidências se dão somente ao núcleo do projeto literário expandido. Porém, não é possível dissociar o projeto desse livro em específico de seus desdobramentos. As relações internas e externas do romance se prendem de modo dialético, e sua síntese, maior que a simples soma das partes, é uma matéria que precisa de um campo literário um pouco maior para se acomodar.

Mais que uma extensão de campo no sentido proposto por Rosalind Krauss, $O$ Grifo de Abdera se expande como uma duplicata de realidades. Uma delas necessariamente contida nos limites da obra, mas que aponta o tempo todo para fora desses limites. A realidade multiplicada por Mutarelli faz com que o leitor, ao conhecer um livro, imediatamente conheça outro, em tudo similar àquele, mas com um autor diferente, de um pseudônimo. E obras de autores diferentes são entendidas de forma diferente.

...o nome do autor funciona para caracterizar certo modo de ser do discurso: para um discurso, o fato de haver um nome de autor, [...] indica que esse discurso não é uma palavra cotidiana, indiferente, $[\ldots]$ mas que se trata de uma palavra que deve 
ser recebida de uma certa maneira e que deve, e uma dada cultura, receber um certo status (FOUCAULT, 2009, pp. 273-274).

Nomes diferentes são recebidos e percebidos de forma diferente, pois carregam um modo de ser do discurso diferente. Lembremos do apreço ao nome de que fala Lejeune, de que a multiplicação se dá como Lourenço Mutarelli. As múltiplas realidades partem de Mutarelli (e Mauro, Paulo, Oliver, Mundinho), mas se multiplicam somente no leitor.

Assim se desvenda o ser total da escritura: um texto é feito de escrituras múltiplas, oriundas de várias culturas e que entram umas com as outras em diálogo, em paródia, em contestação; mas há um lugar onde essa multiplicidade se reúne, e esse lugar não é o autor, como se disse até o presente, é o leitor... (BARTHES, 2012, p. 64).

Todo texto é criador da multiplicidade das escrituras e das realidades. 0 que Lourenço Mutarelli faz em O Grifo de Abdera é tornar esse efeito causa central da obra, ao mesmo tempo em que comenta e revaloriza toda sua carreira. Todos os dispositivos e ações literárias dessa obra levam ao destaque do múltiplo, e de como os diversos se multiplicam em experiências próximas, mas novas. O círculo se completa, mas o ponto de chegada é um lugar novo, diferente daquele de onde se partiu.

\section{referências}

BARTHES, Roland. A Preparação do Romance: Volume II. Trad. Leyla PerroneMoisés. São Paulo: Wmf Martins Fontes, 2005.

. O Rumor da Língua. Trad. Mario Laranjeira. São Paulo: Wmf Martins Fontes, 2012.

BROERING, Pedro Franz. Incidente em Tunguska. 2015. 120 f. Dissertação (Mestrado em Artes Visuais) - Universidade do Estado de Santa Catarina, Florianópolis, 2015. 
CARNEIRO, Maria Clara. Luto e Escritura em A Câmara Clara de Roland Barthes. Dissertação (Mestrado em Letras Neolatinas) - Universidade Federal do Rio de Janeiro, Rio de Janeiro, 2007.

CASTANHO, Renata Manoni de Mello. 'Fechem este maldito livro': a insuficiência da escrita em $\mathrm{O}$ grifo de Abdera. Dissertação (Mestrado em Teoria Literária e Literatura Comparada) - Universidade de São Paulo, São Paulo, 2018.

EISENSTEIN, Sergei. O sentido do filme. 2 ed. Trad. Teresa Otoni. São Paulo: Jorge Zahar Editora, 2002.

FOUCAULT, Michel. "O que é um autor?". In: Ditos e escritos III - Estética: música e literatura, pintura e cinema. Trad. Inês Autran Dourado Barbosa. 2 ed. Rio de Janeiro: Forense Universitária, 2009, pp. 264-298.

GARRAMUÑO, Florencia. Frutos estranhos: sobre a inespecificidade na estética contemporânea. Trad. Carlos Nougué. Rio de Janeiro: Rocco, 2014.

GIDE, André. Os Moedeiros Falsos. Trad. Mario Laranjeira. São Paulo: Estação Liberdade, 2009.

GROENSTEEN, Thierry. O Sistema dos Quadrinhos. Trad. Érico Assis e Francisca Ysabelle Manríquez Reyes. Nova Iguaçu: Marsupial, 2015.

GUSMAN, Sidney (org.). Universo HO Entrevista. Belo Horizonte: Nemo, 2015.

ISABELINHO, Domingos. Comics' Expanded Fields and Other Pet Peeves. Hooded Utilitarian, 12 ago. 2011. Disponível em: <https://www. hoodedutilitarian.com/2011/08/comics-expanded-field-and-other-petpeeves/>. Acesso em: 25/04/2020.

KAFKA, Franz. A Metamorfose. Trad. Petê Rissatti. São Paulo: Autofágica, 2019.

KRAUSS, Rosalind. A Escultura no Campo Ampliado. Arte e Ensaios (UFRJ), Rio de Janeiro, n. 17, pp. 128-137, 2008. Disponível em: <https://www.ppgav. eba.ufrj.br/wp-content/uploads/2012/01/ae17 Rosalind Krauss.pdf>.

Acesso em: 07/01/2020. 
LEJEUNE, Philippe. O Pacto Autobiográfico: de Rousseau à Internet. Trad. Jovita Maria Gerheim Noronha e Maria Inês Coimbra Guedes; Org. de Jovita Maria Gerheim Noronha. Belo Horizonte: UFMG, 2008.

MOTA, Lia Duarte. Performance em O Grifo de Abdera, de Lourenço Mutarelli. Fórum de Literatura Brasileira Contemporânea (UFRJ), Rio de janeiro, v. 8, n. 16, pp. 141-158, 2016. Disponível em: <https://revistas.ufrj. br/index.php/flbc/article/view/17321>. Acesso em: 09/01/2020.

MUTARELLI, Lourenço; MOREIRA, Flavio; COSTA, Olavo; SAIKI, Fernando. O Astronauta ou Livre Associação de um Homem no Espaço. Campinas: Zarabatana, 2010.

MUTARELLI, Lourenço... [et al.]. O Grifo de Abdera. São Paulo: Companhia das Letras, 2015.

MUTARELLI, Lourenço. A Arte de Produzir Efeito Sem Causa. São Paulo: Companhia das Letras, 2008.

. A Caixa de Areia ou Era Dois em Meu Quintal. São Paulo: Devir, 2006. . Capa Preta. São Paulo: Comix Zone, 2019.

. Diomedes. São Paulo: Quadrinhos na Cia., 2012.

. EuTe Amo Lucimar. São Paulo: Vortex, 1994.

. "Mutarelli em Serigrafia". Estúdio Invertido. Curitiba: 30 out. 2015b. Disponível em: <https://estudioinvertido.com.br/mutarelli-em-serigrafia/>. Acesso em: 12/01/2020.

. O Cheiro do Ralo. São Paulo: Devir, 2002.

. O Filho Mais Velho de Deus e/ou O Livro IV. São Paulo: Companhia das Letras, 2018.

. O Natimorto: Um Musical Silencioso. São Paulo: DBA, 2004.

. O Natimorto: Um Musical Silencioso. São Paulo: Companhia das Letras, 2009.

. OTeatro das Sombras. São Paulo: Devir, 2007.

. Quando Meu Pai Se Encontrou Com o ET Fazia um Dia Quente. São Paulo: Companhia das Letras, 2011. 
. Transubstanciação. São Paulo: Dealer, 1991.

. Transubstanciação. 2 ed. São Paulo: Devir, 2001.

Artigo recebido em: 14/01/2020

Aceito em: 15/06/2020 